\title{
A study on the vibration control of an ultra-high performance concrete pedestrian cable stayed bridge
}

\author{
Y. J. Kim, W. J. Chin, E. S. Choi, J. Y. Kang \& B. S. Kim \\ Structural Engineering \& Bridge Research Division, \\ Infrastructure Research Department, \\ Korea Institute of Construction Technology, Korea
}

\begin{abstract}
The first pedestrian cable stayed bridge using ultra-high performance concrete (UHPC) has been designed and constructed in Korea. Our research team want to verify the practicability and feasibility of cable stayed UHPC highway bridges by means of the actual erection of a pedestrian cable stayed UHPC bridge as a test bed. According to the analysis and the preliminary vibration test of the pedestrian cable stayed UHPC bridge constructed, the results indicated that satisfactory serviceability in terms of vibration was secured for most of the pedestrian walking load cases. However, some responses exceeding the limiting criteria occurred in the case of impacts induced by the jumping of a pedestrian. Accordingly, TMDs (Tuned Mass Dampers) were installed on the parapet of the bridge in order to reduce vibrations. The TMD performance verification test showed that the maximum acceleration response of $0.186 \mathrm{~g}$, measured prior to the installation of the TMDs, reduced by more than $49 \%$ after the installation of the TMDs to reach a value of $0.095 \mathrm{~g}$, satisfying the limiting criteria of $0.1 \mathrm{~g}$ in Korea.
\end{abstract}

Keywords: ultra high performance concrete, cable stayed bridge, vibration control, TMD.

\section{Introduction}

There are very few applications of UHPC (Ultra High Performance Concrete) for bridge structures. In Korea, a typical example is the Seonyu pedestrian girder 
bridge, erected in 2002 using French technology. In foreign countries, the Sherbrooke pedestrian girder bridge, built in 1997 in Canada, has pioneered the application of UHPC for bridges. This example was followed by the Shepherds Bridge in Australia, the Papatoetoe station viaduct in New Zealand, the Chabotte Bridge in France and the Sakata Mirai pedestrian bridge in Japan. Currently, KICT (Korea Institute of Construction technology) is conducting a project called "SUPER BRIDGE 200 - Development of Low Cost and Long Life Hybrid Cable Stayed Bridge". This project aims to reduce the construction and maintenance costs of long-span bridges by $20 \%$ and double their lifetime through the exploitation of UHPC.

The first pedestrian cable stayed bridge using UHPC has been designed and constructed in Korea. The $180 \mathrm{MPa}$ class UHPC is the fruit of the research performed by the Korea Institute of Construction Technology (KICT). This bridge has particular meaning, since it is the first pedestrian cable stayed bridge applying UHPC and also because it adopts the hybrid concept. The hybrid concept stands for the optimized exploitation of materials, that is, UHPC is applied for the deck and steel is used for the upper part of the pylon to anchor the cables, while ordinary concrete is adopted for the end slab in order to achieve balance of the forces. This pedestrian bridge constitutes a unique and creative initiative, which has been realized by our own technology and provides a test bed demonstrating that the economically efficient construction of long-span bridges can be achieved through the use of UHPC. Our research team want to verify the promising feasibility and applicability of UHPC cable stayed bridges through the erection of this pedestrian cable stayed bridge.

The natural frequencies, vibration acceleration and dynamic displacement of the UHPC cable stayed bridge were measured during a preliminary dynamic test. Due to the pedestrian cable stayed bridge being a cantilevered structure, vibrations exceeding the vertical vibrational criteria were observed. Accordingly, a vibration control system using a vertical vibration control device was also proposed.

\section{Pedestrian cable stayed UHPC bridge}

The ordinary section of the upper girder was planned as a precast girder using UHPC with compressive strength of $180 \mathrm{MPa}$ (Fig 1). The segments of the precast girder were connected using $20 \mathrm{~mm}$ steel bars after having been epoxybonded. The section contiguous to the pylon was planned to be cast-in-place concrete considering the connection with the pylon. An edge girder was selected for the cross-section of the upper girder in order to develop the most compressive performance of UHPC and the depth of the deck was minimized. PHC piles were applied. The SDA method, using steel pipe casing, was chosen for the pile foundation to prevent the collapse of the wall of the boring, since the bed rock stood at a depth of $24.5 \mathrm{~m}$. This choice was also governed owing to the small vibration and noise produced by the method, considering the neighbouring buildings. Anchor plates were welded at the top of the pylon to fix the cables. 


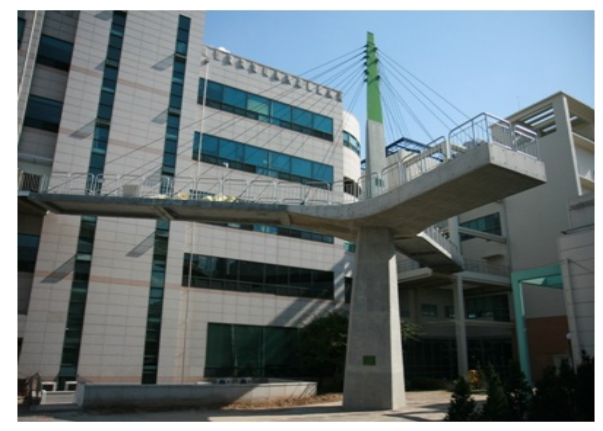

Figure 1: $\quad$ Pedestrian cable stayed UHPC bridge.

The joint between steel and concrete was conceived as a monolithic structure by installing shear keys at the bottom plate and welding the reinforcing bars of the concrete section to the plate. High strength concrete of $40 \mathrm{MPa}$ was applied for the upper part of the pylon and ordinary concrete of $24 \mathrm{MPa}$ for the bottom of the girder. An OSS cable system (Pfeifer) was adopted owing to its appropriateness for a small scale pedestrian bridge. The cables exhibited a diameter of $20.1 \mathrm{~mm}$ and allowable stress of 1,500 $\mathrm{MPa}$.

\section{Vibration control of the pedestrian cable stayed UHPC bridge}

\subsection{Introduction}

The current vertical vibration acceleration of the pedestrian cable stayed UHPC bridge exceeds the limits of $0.1 \mathrm{~g}$ (Design, Construction and Maintenance Manual for Short span bridge and Pedestrian bridge, 2001), since the preliminary vibration test revealed that the maximum vibration acceleration reached approximately $0.11 \mathrm{~g}$. Accordingly, TMDs (Tuned Mass Dampers) were installed on the parapet of the pedestrian cable stayed bridge in order to enhance the vibration serviceability during crossing of the bridge by reducing the vertical acceleration below $0.1 \mathrm{~g}$. The installation of the TMDs was conducted according to the following sequence.

(1) Determination of the characteristics and manufacture of the TMDs

- Design (determination of dimensions and characteristics) and fabrication after execution of three-dimensional structural analysis and preliminary vibration test;

- Testing of the manufactured TMDs at the factory;

- Selection of the location for the installation of the TMDs.

(2) Installation of the TMDs for the pedestrian cable stayed bridge;

- Installation of a total of 4 TMDs (2 TMDs in both directions) on the bridge.

(3) Execution of performance verification test.

The TMD is a variant of the dynamic vibration absorber applied in mechanical engineering adapted to civil structures. This device absorbs the 

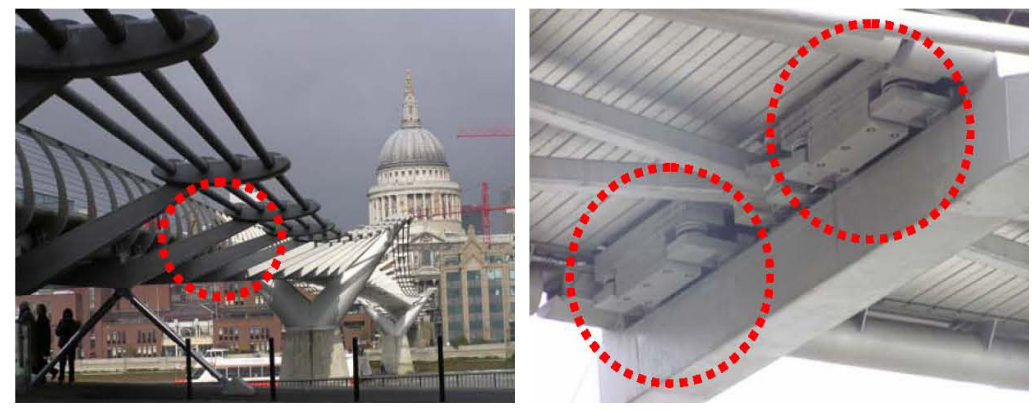

Figure 2: $\quad$ Installation example of TMDs (Millennium Bridge, London).
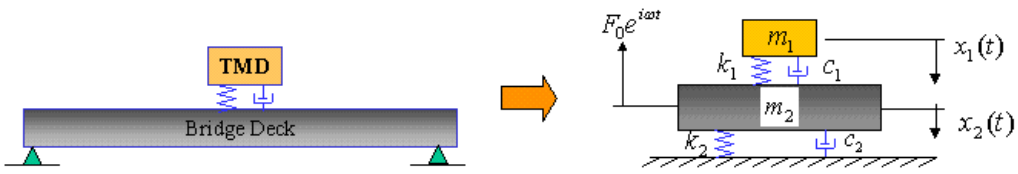

Figure 3: Two DOFs model of a bridge equipped with TMDs.

vibration of the main structure (bridge) by tuning the natural frequency of the TMD to that of the main structure. In general, the TMD has a weight corresponding to $1 \%$ of the structure. This device presents the advantages of being semi-permanent and, as a passive control system, of not requiring electric power. Owing to these advantages, the TMD has seen numerous applications in bridge structures, such as the Millennium Bridge in London, UK, the Bellagio Pedestrian Bridge of Las Vegas in Nevada, USA, the Yokohama Bay Bridge in Japan, the Petronas Towers Sky Bridge in Kuala Lumpur, Malaysia, and the Kessock Bridge in the UK. TMDs were also installed in the Seonyu Bridge, the first UHPC footbridge in Korea.

The TMD for footbridges improves the serviceability by reducing the vibration of the footbridge through the efficient absorption of the energy transmitted by the external load (walking load). The TMD, as a typical passive vibration control device using inertial force, does not require external power supply and exhibits stable behaviour. The TMD is a system fixed to the structure to be controlled and can be modelled as shown in Figure 3, assuming that the external load is a harmonic function $F_{0} e^{i \omega t}$.

$$
\left[\begin{array}{cc}
0 & m_{2} \\
m_{1} & 0
\end{array}\right]\left\{\begin{array}{l}
\ddot{x}_{1} \\
\ddot{x}_{2}
\end{array}\right\}+\left[\begin{array}{cc}
-c_{1} & 2 c_{2} \\
c_{1} & -c_{1}
\end{array}\right]\left\{\begin{array}{l}
\dot{x}_{1} \\
\dot{x}_{2}
\end{array}\right\}+\left[\begin{array}{cc}
-k_{1} & k_{1}+k_{2} \\
k_{1} & -k_{1}
\end{array}\right]\left\{\begin{array}{c}
x_{1} \\
x_{2}
\end{array}\right\}=\left\{\begin{array}{c}
F_{0} e^{i \omega t} \\
0
\end{array}\right\}
$$

Equation (1) formulates the governing equation of motion of a two DOFs system of a bridge equipped with TMDs.

To summarize the principle of vibration control, if the TMD is tuned to the natural frequency of the main structure, the TMD vibrates in a direction opposite 
to the external load and eliminates the vibration of the main structure by absorbing the vibration energy. The function of the TMD is maximized when the main structure enters into resonance or vibrates in a similar state. Theoretically, if both frequencies coincide exactly, the amplitude of the vibration of the main structure can be eradicated and set to zero as shown above. The TMD is composed typically by a mass, spring, damper, frame and other substructures. The device should be installed at the position experiencing the largest vibration in order to develop the highest vibration control effect. In the case of flexible structures, such as steel footbridges, a vibration control effect larger than $40 \%$ can be expected.

\subsection{Dynamic characteristics of the pedestrian cable stayed UHPC bridge}

A three-dimensional finite element analysis was performed using SAP2000, considering the pedestrian cable stayed bridge before the installation of TMDs (Fig 4).

(1) Structural mass: $225.91 \mathrm{kN} \cdot \mathrm{sec}^{2} / \mathrm{m}$

(2) Principal mode of structure: 1 st mode

(3) 1st modal natural frequency: $2.05 \mathrm{~Hz}$

(4) 1 st modal period: $0.49 \mathrm{sec}$

(5) 1st modal mass participation factor: $94.8 \%$

(6) $1 \mathrm{st}$ modal mass: $214.16 \mathrm{kN} \cdot \mathrm{sec}^{2} / \mathrm{m}$

The analysis results show that 1 st mode is vertical and its modal natural frequency is $2.05 \mathrm{~Hz}$.

A dynamic test by pedestrian walking and jumping was conducted for the UHPC pedestrian cable stayed bridge. It can be seen that an identical natural frequency of $1.91 \mathrm{~Hz}$ was estimated during the running of two pedestrians (Chin et al. [4]).

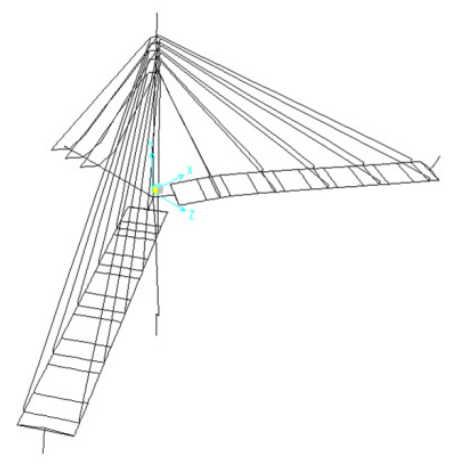

Figure 4: Three-dimensional model. 
Table 1: $\quad$ Specifications of the TMDs.

\begin{tabular}{|c|c|}
\hline Specifications & TMD \\
\hline Design weight & $264 \mathrm{kgf} \times 4$ units \\
\hline Frequency ratio, $f_{R}$ & $f_{R}=1 /(1+\mu)=0.995$ \\
\hline Design natural frequency & $2.05 \mathrm{~Hz}$ \\
\hline Damping ratio & $\zeta_{T}=\sqrt{\frac{3 \mu}{8(1+3 \mu)}}=0.04$ \\
\hline
\end{tabular}
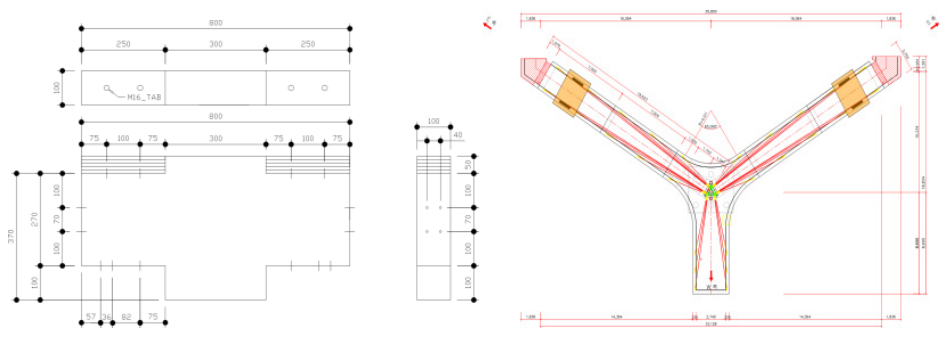

Figure 5: Dimensions and locations of the TMDs.

Since an exciting load with a frequency of $2 \mathrm{~Hz}$ is applied during the walking of a pedestrian, the installation of TMDs is recommended to prevent the occurrence of resonance.

\subsection{Design of the vibration control device}

The moving mass of the TMD was decided as $0.5 \%$ of the $1^{\text {st }}$ modal effective mass. That is, $214.16 \times 0.005=1.0708 \mathrm{kN} \cdot \mathrm{sec}^{2} / \mathrm{m}$. A total of 4 TMDs were installed with 2 TMDs at each end of the pedestrian cable stayed bridge. The mass of each TMD is $1.0708 / 4=0.2677 \mathrm{kN} \cdot \mathrm{sec}^{2} / \mathrm{m}$, which corresponds to a moving mass of $0.2677 \times 9.806=263 \mathrm{kgf}$. Accordingly, the design moving mass of the TMDs was adjusted to $264 \mathrm{kgf}$, considering the processing of steel. The modified mass ratio is $\mu=1.0708 / 214.16=0.005$.

\subsection{Installation and verification test of the TMDs on the pedestrian cable stayed bridge}

\subsubsection{Installation of the TMDs}

Two TMDs were installed at each end of the cantilevered beams of the footpath of the UHPC pedestrian cable stayed bridge so as to maximize their effects. Their positions were also selected to prevent interference with the stay cables. Since the footbridge presents a longitudinal slope, attention was paid to the horizontality during the installation of the TMDs. The devices were strongly fixed through anchors inserted in holes perforated in the curb on the inner side of the parapet. Transparent tempered glass was used to cover the TMDs and ease maintenance and monitoring. 


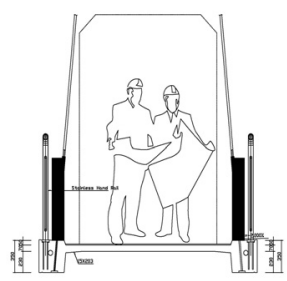
Figure 6: TMDs installed on the kerb.

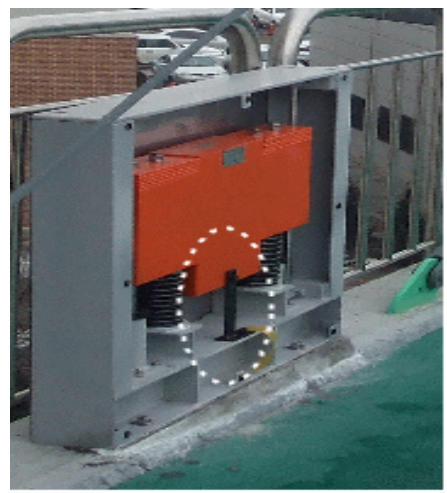

$\leftarrow$ No control (locking)

Control (unlocking)

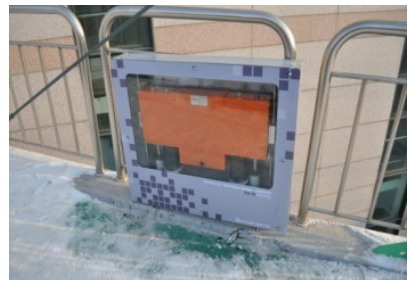

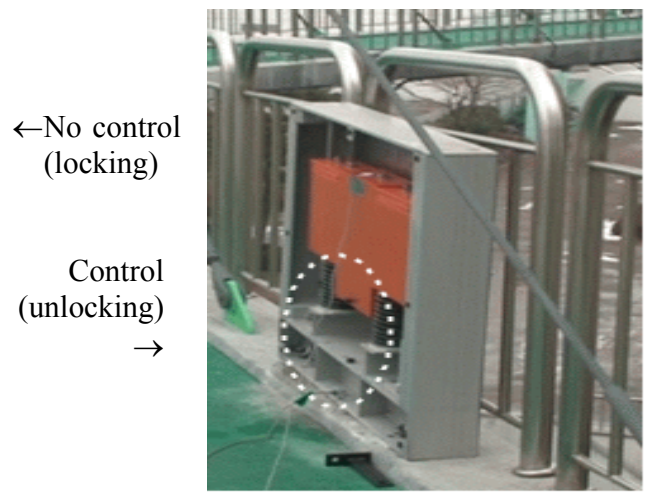

Figure 7: Control device for TMDs.

\subsubsection{Verification test for the TMDs}

A field performance verification test was conducted to check the efficiency of the performance of the TMDs after their installation on the pedestrian cable stayed bridge. To that goal, the vibration reducing effect was verified by measuring the acceleration responses before and after the operation of the TMDs using the lock device installed on the moving mass of the TMDs (Fig 7). The vibration of the footbridge was measured after inducing artificial vibration by applying a live load on the bridge. Loading was applied at the cantilever ends of the footbridge under the conditions illustrated in Figures 8 to 10, applying loading by pedestrians.

Passive vibration control devices, that is TMDs, were designed and installed at the end joints of the footbridge to control the undesirable vibrations occurring in the UHPC pedestrian cable stayed bridge. As could be seen in the test results, the maximum acceleration response before the installation of the TMDs reached $0.186 \mathrm{~g}$ and exceeded the limit of $0.1 \mathrm{~g}$ recommended for footbridges. After the installation of the TMDs, the acceleration response reduced to below $0.1 \mathrm{~g}$ and proved the effectiveness of the vibration reduction. In addition, apart from the vibration reduction effect, the shortening of the vibration duration could also be verified. 

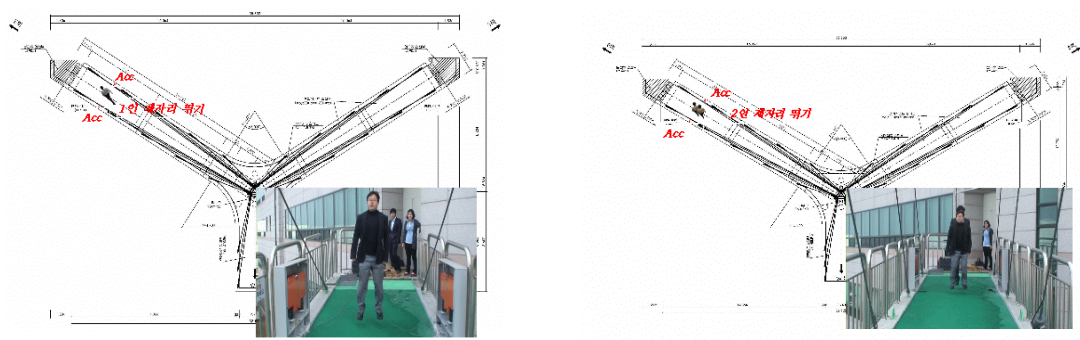

Figure 8: Stand-running of 1 pedestrian. Figure 9: Stand-running of 2 pedestrians.

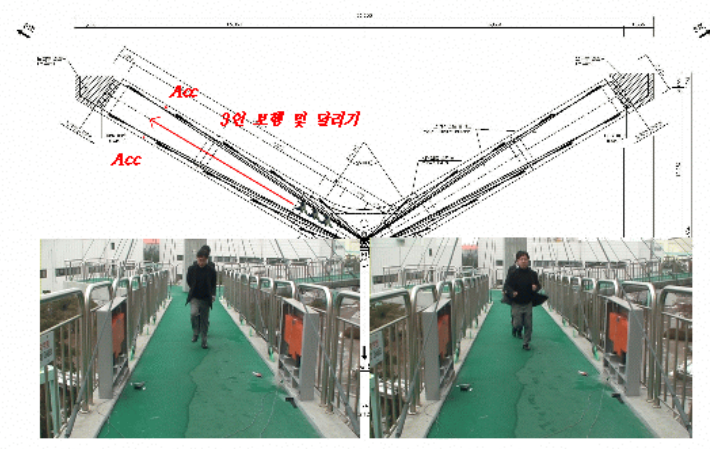

Figure 10: Walking and running of 3 pedestrians.

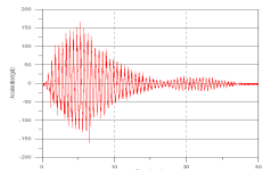

Before TMD operation

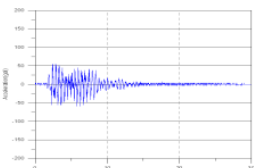

After TMD operation

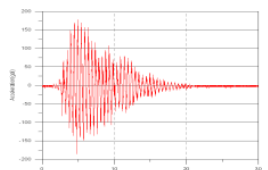

Before TMD operation

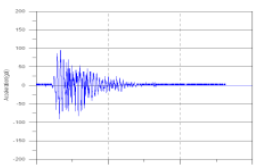

After TMD operation

Figure 11: Stand-running of 1 Figure 12: Stand-running of 2 pedestrian (main building 1). pedestrians (main building 1).

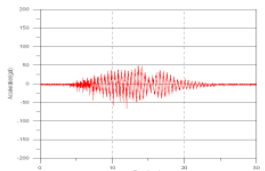

Before TMD operation

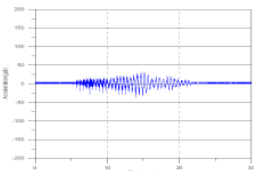

After TMD operation

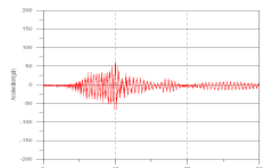

Before TMD operation

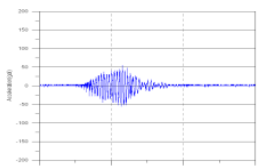

After TMD operation

Figure 13: Walking of 1 pedestrian Figure 14: Running of 3 pedestrians (main building 1). (main building 1). 
Table 2: $\quad$ Measured vertical vibration acceleration (toward main building 1).

\begin{tabular}{|c|c|c|}
\hline \multirow{2}{*}{ Case } & \multicolumn{2}{|c|}{ Vertical vibrational acceleration (g) } \\
\cline { 2 - 3 } & Before operation of TMD & After operation of TMD \\
\hline Stand-running of 1 pedestrian & 0.148 & 0.058 \\
\hline Stand-running of 2 pedestrians & 0.181 & 0.090 \\
\hline Walking of 3 pedestrians & 0.054 & 0.037 \\
\hline Running of 3 pedestrians & 0.058 & 0.052 \\
\hline
\end{tabular}

(measurement units converted to $100 \mathrm{gal}=0.1 \mathrm{~g}$ )

Table 3: $\quad$ Measured vertical vibration acceleration (toward main building 2).

\begin{tabular}{|c|c|c|}
\hline \multirow{2}{*}{ Case } & \multicolumn{2}{|c|}{ Vertical vibrational acceleration (g) } \\
\cline { 2 - 3 } & Before operation of TMD & After operation of TMD \\
\hline Stand-running of 1 pedestrian & 0.165 & 0.059 \\
\hline Stand-running of 2 pedestrians & 0.186 & 0.095 \\
\hline Walking of 3 pedestrians & 0.066 & 0.037 \\
\hline Running of 3 pedestrians & 0.066 & 0.055 \\
\hline
\end{tabular}

(measurement units converted to $100 \mathrm{gal}=0.1 \mathrm{~g}$ )

\section{Conclusions}

A pedestrian cable stayed bridge using KICT-UHPC has been designed and erected inside the site of the Korea Institute of Construction Technology (KICT). Our research team has verified the practicability and feasibility of cable stayed UHPC highway bridges by means of the actual erection of a pedestrian cable stayed UHPC bridge as a test bed. According to the analysis and the preliminary vibration test evaluated, the results indicated that satisfactory serviceability in terms of vibration was secured for most of the pedestrian walking load cases. However, some responses exceeding the limiting criteria occurred in the case of impacts induced by the jumping of the pedestrian. Accordingly, TMDs were installed on the parapet of the bridge as a measure to reduce vibrations. The TMD performance verification test showed that the maximum acceleration response of $0.186 \mathrm{~g}$, measured prior to the installation of the TMDs, reduced by more than $49 \%$ after the installation of the TMDs, to reach a value of $0.095 \mathrm{~g}$ and thereby satisfying the limiting criteria of $0.1 \mathrm{~g}$ in Korea. Further studies are required to apply diversified test variables related to the vibration test of the footbridge and for the evaluation of the vibration characteristics of the pedestrian cable stayed UHPC bridge, such as the maximum acceleration, dynamic deflection and modal shapes through various vibration tests and analyses. Moreover, future performance evaluation tests on the footbridge equipped with the vibration control device, as well as dynamic analyses and lateral vibration tests, will provide precious and reliable data with regard to the dynamic characteristics of the UHPC pedestrian cable stayed bridge. 


\section{Acknowledgement}

This study was carried out as part of the "R\&D on Design and Construction System of Hybrid Cable Stayed Bridges" at the Korea Institute of Construction Technology. The authors express their gratitude for the support.

\section{References}

[1] Korea Institute of Construction Technology (KICT), Development of integrated technology for hybrid cable stayed bridge, Research report, 2009.

[2] Chin, W.J. et al, Evaluation of the dynamic characteristics of UHPC pedestrian cable stayed bridge (Super Bridge 1), Proc. of KSCE Annual Confer., 2009.

[3] Ministry of Construction and Transportation, Development of bridge girder using ultra high performance cementitious composite materials, Report of Construction Core Technology R\&D Program, 2003.

[4] Chin, W.J. et al, Experimental study on dynamic characteristics of UHPC pedestrian cable stayed bridge, Proc. of HPSM 2010, 2010.

[5] Seoul City, Design, Construction and Maintenance Manual for Short span bridge and Pedestrian bridge, 2001

[6] Korea Infrastructure Safety and Technology Corporation (KISTEC), Establishment of evaluation procedure for the vibration and deflection of bridges in terms of serviceability, Final report of the Construction Innovation Program, 2000.

[7] K-enc Research Institute, Report of the installation of TMD (EC-FTMD) (UHPC pedestrian cable stayed bridge at KICT), 2009.

[8] Lee, J.I. et al, Efficient vibration control of footbridge using TMD, Proc. of KSCE Annual Confer., 2002. 